This is a peer-reviewed, accepted author manuscript of the following research article: Jacob, A., De Oliveira, J. A., Mehmanparast, A., Hosseinzadeh, F., \& Berto, F. (2018). Should residual stresses be taken into account in structural integrity assessment of offshore monopiles? In Structures, Safety, and Reliability (Proceedings of the International Conference on Offshore Mechanics and Arctic Engineering - OMAE; Vol. 3). American Society of Mechanical Engineers (ASME). https://doi.org/10.1115/OMAE2018-78519

\title{
SHOULD RESIDUAL STRESSES BE TAKEN INTO ACCOUNT IN STRUCTURAL INTEGRITY ASSESSMENT OF OFFSHORE MONOPILES?
}

\author{
Anais Jacob ${ }^{1}$, Jeferson Oliveira ${ }^{2 *}$, Ali Mehmanparast ${ }^{1}$, Foroogh Hosseinzadeh ${ }^{2}$, Filippo Berto ${ }^{3}$ \\ ${ }^{1}$ Offshore Renewable Energy Engineering Centre, Cranfield University, Bedfordshire, MK43 OAL, UK \\ ${ }^{2}$ The Open University, Materials Engineering, Milton Keynes, MK7 6BJ, UK \\ ${ }^{3}$ Norwegian University of Science and Technology (NTNU), Trondheim, Norway \\ *Corresponding author: jeferson.oliveira@open.ac.uk
}

\begin{abstract}
A key challenge in the Offshore Wind industry is assuring the life-cycle structural integrity (design against failure) of wind turbine foundation monopiles. This is due to harsh environmental aspects as well as the loading regime (i.e. constant exposure to wave and wind forces introducing both fatigue and corrosion damage). Welding is a widely used joining technique for the manufacturing of offshore monopile structures. However, this is an aggressive process that introduces high levels of residual stress in the manufactured part, which may lead to reduced fatigue life, corrosion cracking resistance and accelerated degradation mechanisms. This study introduces a measurement-informed strategy that could be used towards developing a more reliable structural integrity assessment procedure for offshore monopile structures by taking into account the effect of residual stresses. A welded mock-up, $90 \mathrm{~mm}$ thick, $2600 \mathrm{~mm}$ wide and $800 \mathrm{~mm}$ long plate, was fabricated using a typical double $\mathrm{V}$ welding procedure following current industrial practice. The contour method of residual stress measurement was employed to map residual stresses in the welded mock-up as well as in the CT specimens extracted from the weld region of the plate for future fatigue tests. Residual stress measurement results show that the mock-up plate contained tensile residual stresses above yield in the core of the weld, while the extracted CT specimens had significantly lower residual stresses. These results indicate that if the initial residual stresses are not carefully considered during fatigue or corrosion cracking tests, the results from the CT specimens alone could result in misleading structural life estimations.
\end{abstract}

Keywords: residual stress, monopile, fatigue crack growth, offshore wind, contour method

\section{Introduction}

Wind energy is a renewable energy source that plays an increasingly important role in mitigating greenhouse gas emissions, reducing global temperature rise and providing energy security. However, one of the important challenges in offshore wind industry is the structural integrity of wind turbine foundation.

Monopile is the most widely used foundation type in shallow water offshore wind farms [1-3], which operate in harsh offshore environment. In addition, monopiles are subjected to wind, wave and sea current cyclic loads; hence they have to be designed against fatigue and stress-corrosion failure.

Welding residual stresses notably influence fatigue crack growth (FCG) behaviour of engineering structures. This effect is more pronounced in the near-threshold regime, while they eventually vanish when the crack length is substantial in relation to the cross-section [4-8].

Crack initiation and growth in monopiles tend to primarily occur at circumferential welds [9]. A significant effort has been made in the SLIC JIP (Structural Lifecycle Industry Collaboration Joint Industry Project) to characterise the FCG behaviour of these welded structures [9-10]. However, due 
to the lack of data available at the time, the effect of residual stress on FCG particularly in the nearthreshold regime was not considered.

The lack of residual stress data leads to high level of uncertainty and conservatism in the existing codes and standards for the design process or lifetime estimation and structural integrity assessment of monopiles [11-13]. This is particularly important because no post-weld heat treatment is performed on monopiles because of size and cost issues. Reliably charactering welding residual stresses will lead to reliable estimate of fatigue crack initiation and propagation in monopiles particularly at circumferential weld regions in which the cracks are often initiated.

In this paper, for the first time, we present residual stress characterisation using the contour method on a large welded mock-up, in the form of a plate, typical of offshore wind monopile weldment. We also conducted contour method measurements on a compact tension, $C(T)$, extracted from the large welded mock-up. $\mathrm{C}(\mathrm{T})$ fracture mechanics test specimens are typically used in characterising FCG behaviour of engineering materials in lab environments. The following sections explain the details of the test specimens and the residual stress measurement techniques performed in this work. The results from these measurements are presented and discussed in terms of the effect of residual stress on fatigue crack growth behaviour of monopile weldments in small-scale laboratory samples and real-size scale structures.

\section{Specimens}

The large welded mock-up: The material used for the large mock-up is EN-10225:09 S355 $\mathrm{G} 10+\mathrm{M}$, which is widely used in the fabrication of offshore structures including offshore wind turbine monopiles [14]. To replicate the existing welds in monopiles for the mock-up, multi-pass submerged arc welding (SAW) tandem-twin process was chosen to increase deposition rates and productivity. The solid wire electrode was EN ISO 14171-A (EN 756): S3Si and the chosen flux was EN ISO 14174: SA FB $155 \mathrm{AC} \mathrm{H}$. Filler metal was F7A8-EH12K AWS class and Esab OK12.32/SAF Oerlikon OP121TT trade. Multi-pass welding was conducted on double V-grooved hot-rolled plates with $90 \mathrm{~mm}$ thickness, 800 $\mathrm{mm}$ long (in longitudinal direction) and $1300 \mathrm{~mm}$ wide (in transverse directions). Welding was conducted by EEW in Germany, parallel to the rolling direction using run off, thereafter cut, at each end of the plate as shown in Figure 1 (a). No post-weld heat treatment (PWHT) was performed in order to replicate real-life conditions of offshore wind monopile structures. A macrograph of the weld is shown in Figure 1 (b), where the three regions of interest (BM, WM, HAZ) are identified.

(a)

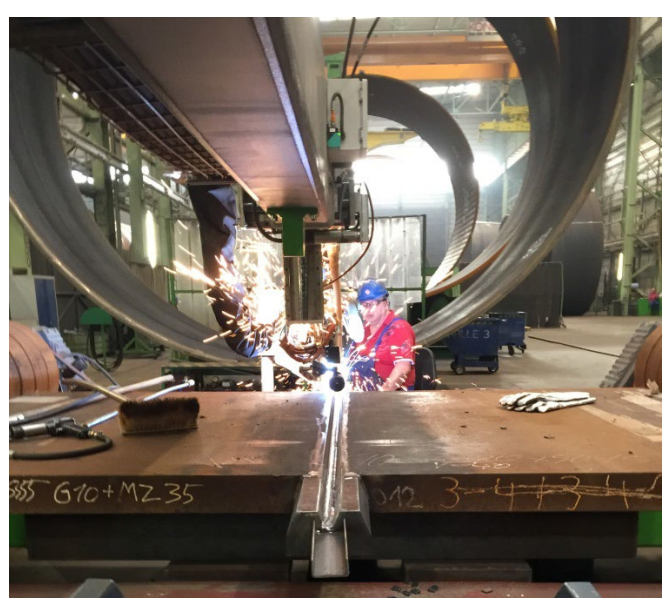

(b)

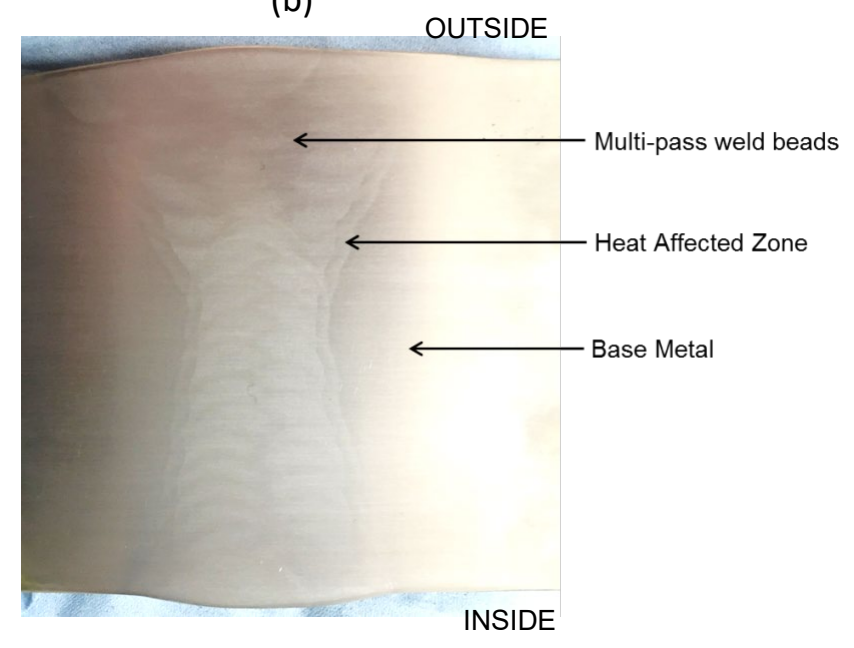

Figure 1: (a) Multi-pass submerged arc welding on S355 G10+M welded mock-up and (b) weld macrograph following polishing and etching the surface of cross-weld extracted slice. 
To facilitate transport of the welded plate, the width of the plate, the transverse dimension, after welding was reduced from $2600 \mathrm{~mm}$ to $600 \mathrm{~mm}$ by flame cutting the BM plates at round $300 \mathrm{~mm}$ away from and at either side of the weld region. The length of the plate along the longitudinal direction was shortened by flame cutting to $600 \mathrm{~mm}$. The section for contour method residual stress characterisation was measured $90 \mathrm{~mm}$ (thickness) $\times 600 \mathrm{~mm}$ (in longitudinal direction) $\times 600 \mathrm{~mm}$ (in transverse direction). A smaller section with $90 \mathrm{~mm}$ (thickness) $\times 200 \mathrm{~mm}$ (in longitudinal direction) $\times$ $600 \mathrm{~mm}$ (in transverse direction) dimensions was prepared for the extraction of a $\mathrm{C}(\mathrm{T})$ specimen and also tensile specimens.

Tensile tests were performed at room temperature on cross-weld specimens using digital image correlation (DIC) to determine the tensile properties of the material. The $0.2 \%$ proof stress is $455 \mathrm{MPa}$ for the BM, $469 \mathrm{MPa}$ for the HAZ and $477 \mathrm{MPa}$ for the WM. Due to the relatively poor resolution of DIC, to measure elastic properties of the material, a tensile test on a round bar sample extracted from the BM was conducted and the Elastic Young's modulus and Poisson's ratio were found to be E = 196 $\mathrm{GPa}$ and $\mathrm{v}=0.3$, respectively. The elastic properties of the WM and HAZ were assumed the same as in the BM.

C(T) Specimens: $C(T)$ specimens extracted from larger weldments are often assumed to be stress-free, hence the effect of any remnant residual stress on characterised fatigue or fracture behaviour is often ignored, which in many cases, leads to errors.

In order to investigate the level of remaining residual stresses in fracture mechanics specimens extracted from the large welded mock-up, a $16 \mathrm{~mm}$ thick slice was extracted from the $90 \mathrm{~mm} \times 200$ $\mathrm{mm} \times 600 \mathrm{~mm}$ welded section, ground, polished and subsequently etched using $10 \%$ Nital solution in order to visualise the weld and HAZ zones.

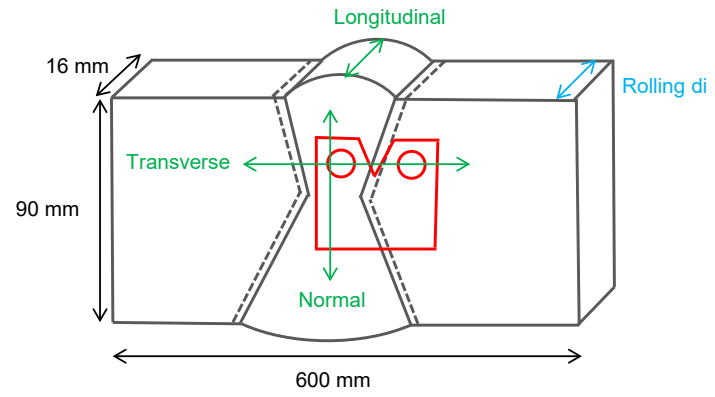

(a)

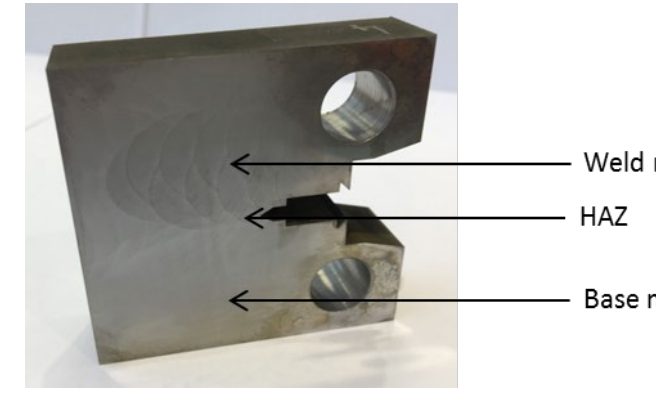

(b)

Figure 2: (a) $C(T)$ specimen extraction location with respect to the welded mock-up (b) Compact tension, $C(T)$, specimen extracted from the welded slice.

Previous studies [9] have shown that the crack initiation in monopiles mainly occurs at the weld toe (in the as-welded condition) and in the HAZ region of the circumferential weld due to lateral wind and wave loads and propagates into the BM in through-thickness direction. Therefore, the orientation in which the $C(T)$ specimen was extracted aimed to replicate the critical condition in the real application, shown in Figure 2.

\section{Residual Stress Measurements}

With the contour method, residual stresses longitudinal to the weld were measured in the large weld mock-up plate, while transverse stresses were measured in the $C(T)$ specimen.

Contour Residual Stress Measurement on the $C(T)$ sample: The contour method [15] measurement on the $C(T)$ sample was performed on the same plane as the neutron diffraction measurements. Prior to the cut, a layer of sacrificial material was attached to the top and bottom surfaces to mitigate the wire entry and exit cutting artefacts [16]. An Agie Charmilles Cut 1000 EDM machine with a $50 \mu \mathrm{m}$ diameter brass wire was used to perform the contour cut and a Zeiss Eclipse 
co-ordinate measuring machine (CMM), fitted with a Micro-Epsilon laser probe and a $2 \mathrm{~mm}$ diameter ruby-tipped Renishaw PH10M touch trigger probe was used for surface deformation measurements with an in-plane point spacing of $25 \mu \mathrm{m}$. In addition, the perimeters of the two cut parts were measured with the touch-probe.

The data sets for opposing cut surfaces were aligned and then averaged [15]. Noise in the displacement profile was smoothed out using a median filter (StressMap's proprietary algorithm). The smoothing level was modulated by varying the 'mask size' between 0.275 and $2.025 \mathrm{~mm}$ in steps of $0.25 \mathrm{~mm}$ and the optimum smoothing level within this range was given by a mask size of $1.525 \mathrm{~mm}$, giving an overall fitting error of just over $7 \mathrm{MPa}$, estimated using the approach in [17].

To calculate the stresses, an FE model was created in Abaqus 6.13 with the geometry of one of the cut halves. The model was meshed using linear hexahedral elements with reduced integration (C3D8R). The mesh at the cut surface was biased from $0.25 \mathrm{~mm}$ near the surface of interest up to $3 \mathrm{~mm}$ on the opposite face. The model was assigned uniform isotropic elastic properties, with a Young's modulus of $196 \mathrm{GPa}$ and Poisson's ratio of 0.3.

The smoothed displacement profile, with a reverse sign, was applied as surface boundary condition on the surface nodes of the FE model of the cut half and an elastic stress analysis was performed. The 2D map of transverse residual stress obtained from the contour method, see Figure 3 , provides a rich set of information about the distribution of residual stress over the expected plane of crack growth in the $C(T)$ sample. The contour map showed the presence of high compressive residual stress at the central region through the thickness of the sample near the crack tip with much lower level of residual stresses further ahead of the notch. An important observation from the 2D crosssectional map of transverse residual stress is the variation of transverse residual stress through the thickness of the sample.

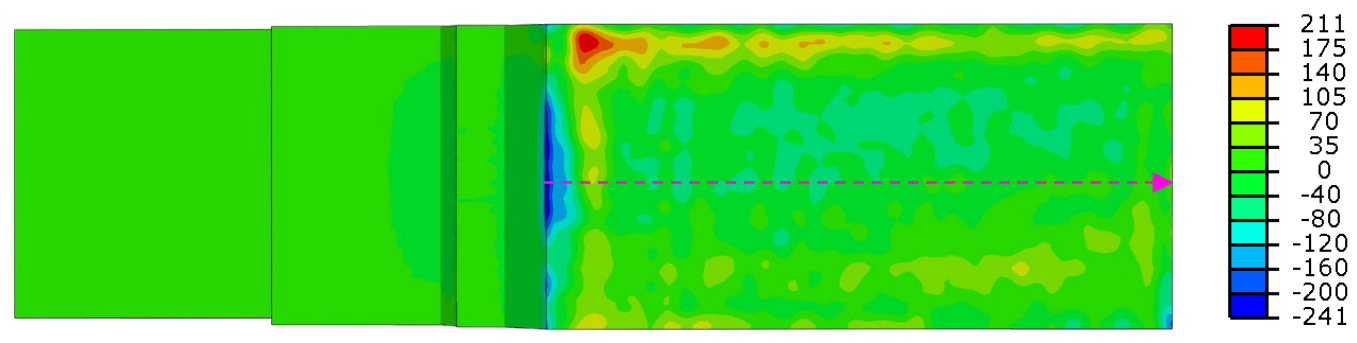

Figure 3: Contour residual stress measurement results along transverse direction of the weld on the $C(T)$ specimen. The stress scale is in MPa. 


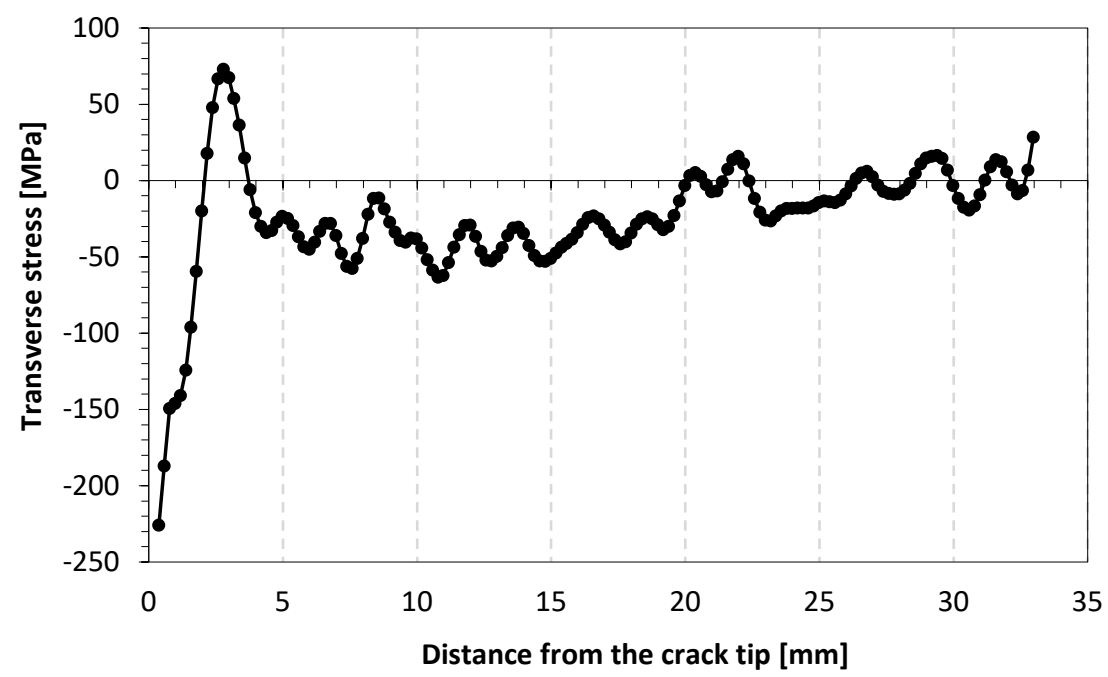

Figure 4: Comparison of transverse residual stress measurements on the $C(T)$ specimen using neutron diffraction and the contour method.

The distribution of transverse stresses measured using the contour method along a line at midthickness of the $C(T)$ sample is plotted in Figure 4.

Results confirmed that transverse residual stresses ahead of the crack tip are predominantly in compression and the level of stresses is about -50 MPa.

Residual stress measurements in the welded mock-up: The contour method was employed to measure residual stresses in the welded mock-up. An Agie Charmilles FI 440 ccS EDM machine was used to perform the cut using a $250 \mu \mathrm{m}$ diameter brass wire. The sample was firmly clamped to the EDM stage. To mitigate plasticity and the so-called bulge error [17-20], the main cut through the weld was performed between two pilot holes and the remaining ligaments were cut afterwards (as shown in Figure 5).

The cut surfaces were measured with the same CMM described above with an in-plane point spacing of $100 \mu \mathrm{m}$. In addition, the perimeters of the two cut parts were measured with the touchprobe.

The same analysis procedure described above was used for obtaining a smoothed displacement map. The smoothing level was modulated by varying the 'mask size' between 3.1 and $10.1 \mathrm{~mm}$ in steps of $1 \mathrm{~mm}$ and the optimum smoothing level within this range was given by a mask size of $6.1 \mathrm{~mm}$. For this mask size, the overall fitting error, estimated using the approach in [17], was below $5 \mathrm{MPa}$. 


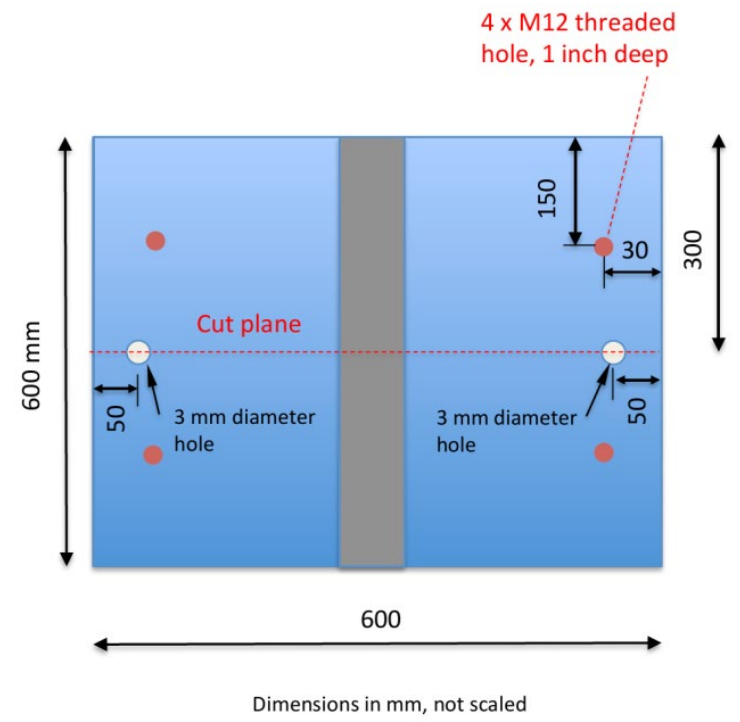

Figure 5: Dimensions of the welded mock-up showing the location of the contour cut plane and pilot holes.

The FE model to back calculate the stresses, was meshed using linear hexahedral elements with reduced integration (C3D8R). The mesh on the cut surface was biased from $1 \mathrm{~mm}$ near the weld up to $3.5 \mathrm{~mm}$ away from the weld. A bias was also applied in the extrusion direction, going away from the cut face, from 0.5 up to $50 \mathrm{~mm}$. The model was assigned uniform isotropic elastic properties, with a Young's modulus of $196 \mathrm{GPa}$ and Poisson's ratio of 0.3.

The smoothed displacement profile, with a reverse sign, was applied as boundary condition on the surface nodes of the simulated cut parts. The resulting 2D map of the stress component normal to the cut surface represents the initial residual stresses distribution acting longitudinally to the weld (See Figure 6).

It can be seen that there are two distinct regions of tensile stress within the weld, which correlate to the double-groove welding sequence. Compressive stresses are observed on the top and bottom faces of the plate away from the weld, while high tensile stresses are present towards the ends of the cross-section (extreme left and right-hand-sides). The compressive stresses, observed at top and bottom faces, are believed to have been introduced as a result of the rolling process that the plates were subjected to before welding. In addition, these compressive stresses may have been intensified to balance the tensile stresses introduced due to the welding process elsewhere within the cross-section. The tensile residual stresses towards the ends of the plate are believed to be the result of the flame cutting operation that was performed to extract the $600 \mathrm{~mm} \times 600 \mathrm{~mm}$ sample out of the larger $(2.6 \mathrm{~m} \times 800 \mathrm{~mm}$ ) welded mock-up. Due to the presence of pilot holes, no deformation data was recorded adjacent to the pilot holes. As a result the provided stress map in these regions is masked and the resulting stress data should not be reported, see Figure 6 .

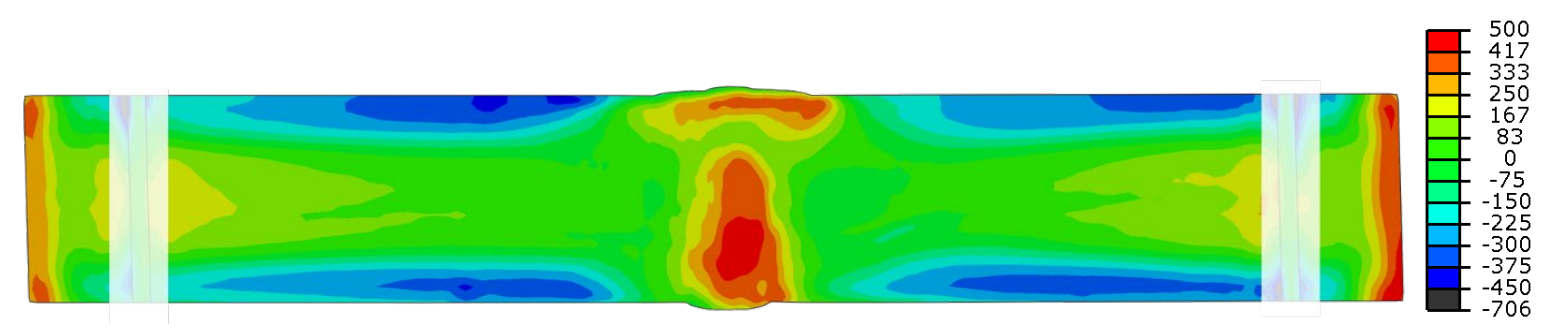

Figure 6: Longitudinal residual stress measurement obtained from the contour method. The stress unit is in MPa. 


\section{Discussion}

Residual Stress Effects on Fatigue Behaviour of C(T) Specimen: The study carried out on a C(T) specimen extracted from a welded plate has shown a non-uniform distribution of transverse residual stresses on the crack plane (i.e. compressive at the mid-thickness and tensile at the outer surfaces). This varying through-thickness residual stress distribution profile subsequently influences the crack propagation rate profile leading to uncertainties in crack growth monitoring in fracture mechanics specimens. The crack length measured on the outer surface may differ to the crack length at the midthickness, depending on the residual stress distribution profile. As the crack propagates, residual stresses redistribute and have their magnitude reduced [21]. However, the presence of residual stress significantly influence the effective threshold stress intensity factor range, $\Delta K_{\text {eff, th }}$, and hence influence the crack initiation and early growth propagation [22]. Therefore, more pronounced effects from residual stresses are expected on the fatigue crack initiation and early stage fatigue crack propagation.

Residual Stress Effects on Fatigue Behaviour of Monopile: There is a pronounced difference in the residual stress magnitude between the $C(T)$ specimen and the large welded mock-up. A difference of $\sim 300 \mathrm{MPa}$ is observed between transverse residual stress in the $\mathrm{C}(\mathrm{T})$ sample and the longitudinal residual stress in the weld mock-up.

Although the normal and transverse components of the residual stresses on the welded mockup are not yet available, a similar difference might be expected in residual stress measurements in transverse direction between the welded mock-up and the $C(T)$ sample. This implies that the transverse residual stresses at circumferential welds in monopiles can be close to the yield stress of the material, which subsequently result in accelerated crack initiation and propagation under corrosion-fatigue loading conditions. According to [23] and based on the measurements performed, it appeared that the maximum and minimum residual stress levels that can occur after welding may be up to the yield strength of the material.

\section{Conclusions}

The design and structural integrity codes and standards for offshore wind structures do not take into account the effect of residual stresses. This study presents residual stress characterisation in structural steel offshore wind monopile weldments using the contour method. For the first time the contour method of residual stress measurement was conducted on a large welded mock-up with typical welding procedure used in the fabrication of monopile structural weldments. This was followed by conducting additional contour method measurements on a standard $C(T)$ specimen extracted from the welded mock-up.

The contour method measurement on the large welded mock-up showed high levels of tensile residual stress in the as-welded condition, while measurements revealed a significant redistribution and reduction in magnitude upon extraction of laboratory samples from large-scale welded structures.

Despite redistributed and reduced the remnant residual stresses in the standard laboratory samples can still be significant enough to have potential impacts on fatigue crack initiation and propagation.

Since fatigue crack initiation and propagation are highly sensitive to the level or residual stresses, by not considering these stresses in all stages of structural integrity assessments, it is inevitable that life predictions will be inaccurate, potentially leading to over-design or even premature failure of offshore monopile structures.

\section{Acknowledgements}

This work was supported by grant EP/L016303/1 for Cranfield University and the University of Oxford, Centre for Doctoral Training in Renewable Energy Marine Structures - REMS 
(http://www.rems-cdt.ac.uk/) from the UK Engineering and Physical Sciences Research Council (EPSRC). Furthermore, valuable contributions of all staffs involved in contour measurements at the Open University are greatly appreciated.

\section{References}

[1] J. Velarde, "Design of Monopile Foundations to Support the DTU 10 MW Offshore Wind Turbine," 2016.

[2] J. van der Tempel, N. F. B. Diepeveen, C. S. D.J., and W. E. de Vries, "Design of support structures for offshore wind turbines," in WIT Transactions on State of the Art in Science and Engineering, vol. 44, 2010, pp. 1-25.

[3] L. Arany, S. Bhattacharya, J. Macdonald, and S. J. Hogan, "Design of monopiles for offshore wind turbines in 10 steps," Soil Dyn. Earthq. Eng., vol. 92, pp. 126-152, 2016.

[4] F. V Lawrence, J. D. Burk, and J.-Y. Yung, "Influence of Residual Stress on the Predicted Fatigue Life of Weldments," in Residual stress effects in fatigue, 1982, vol. STP 776, pp. 3343.

[5] D. V Nelson, "Effect of Residual Stress on Fatigue Crack Propagation," in Residual stress effects in fatigue, 1982, vol. STP 776.

[6] X. Lu, "Influence of Residual Stress on Fatigue Failure of Welded Joints," NC State University, 2003.

[7] P.-Y. Cheng, "Influence of Residual Stress and Heat Affected Zone on Fatigue Failure of Welded Piping Joints," NC STate University, 2009.

[8] J. Krebs and M. Kassner, "Influence of Welding Residual Stresses on Fatigue Design of Welded Joints and Components," Weld. World, vol. 51, no. 7/8, pp. 54-68, 2007.

[9] A. Mehmanparast, F. Brennan, and I. Tavares, "Fatigue crack growth rates for offshore wind monopile weldments in air and seawater: SLIC inter-laboratory test results," Mater. Des., vol. 114, pp. 494-504, 2017.

[10] O. Adedipe, F. Brennan, A. Mehmanparast, A. Kolios, and I. Tavares, "Corrosion fatigue crack growth mechanisms in offshore monopile steel weldments," Fatigue Fract. Eng. Mater. Struct., vol. 40, no. 11, pp. 1868-1881, 2017.

[11] A. Mehmanparast, O. Adedipe, F. Brennan, and A. Chahardehi, "Welding sequence effects on residual stress distribution in offshore wind monopile structures," Frat. ed Integrità Strutt., vol. 35, pp. 125-131, 2016.

[12] Det Norske Veritas AS, "Fatigue Design of Offshore Steel Structures," 2005.

[13] The British Standards Institution, "BSI Standards Publication Guide to methods for assessing the acceptability of flaws in metallic structures," 2015.

[14] Det Norske Veritas AS, "Offshore Standard DNV-OS-B101: Metallic Materials," 2009.

[15] M. B. Prime, "Cross-Sectional Mapping of Residual Stresses by Measuring the Surface Contour After a Cut," J. Eng. Mater. Technol., vol. 123, no. 2, p. 162, 2001.

[16] F. Hosseinzadeh, P. Ledgard, and P. J. Bouchard, "Controlling the Cut in Contour Residual Stress Measurements of Electron Beam Welded Ti-6Al-4V Alloy Plates," Exp. Mech., vol. 53, no. 5, pp. 829-839, 2013.

[17] M. B. Prime, R. J. Sebring, J. M. Edwards, D. J. Hughes, and P. J. Webster, "Laser surfacecontouring and spline data-smoothing for residual stress measurement," Exp. Mech., vol. 44, no. 2, pp. 176-184, 2004.

[18] F. Hosseinzadeh, Y. Traore, P. J. Bouchard, and O. Muránsky, "Mitigating cutting-induced plasticity in the contour method, part 1: Experimental," Int. J. Solids Struct., vol. 94-95, pp. 247-253, 2016.

[19] O. Muránsky, C. J. Hamelin, F. Hosseinzadeh, and M. B. Prime, "Mitigating cutting-induced plasticity in the contour method. Part 2: Numerical analysis," Int. J. Solids Struct., vol. 94-95, pp. 254-262, 2016.

[20] M. B. Prime and A. L. Kastengren, The Contour Method Cutting Assumption: Error 
Minimization and Correction. Experimental and Applied Mechanics, Volume 6, 2010.

[21] C. D. M. Liljedahl, O. Zanellato, M. E. Fitzpatrick, J. Lin, and L. Edwards, "The effect of weld residual stresses and their re-distribution with crack growth during fatigue under constant amplitude loading," Int. J. Fatigue, vol. 32, no. 4, pp. 735-743, 2010.

[22] K. A. Venkata, C. E. Truman, D. J. Smith, and R. C. Wimpory, "Relaxation of residual stresses when extracting a specimen from a dissimilar metal electron beam welded plate," in 7th International Conference on Creep, Fatigue and Creep-Fatigue Interaction, 2016, vol. 7, pp. $19-22$.

[23] Y.-H. Zhang, S. Smith, W. Liwu, and C. Johnston, "Residual stress measurements and modelling," Fatigue Fract. Eng. Mater. Struct., no. 40, pp. 1868-1881, 2017. 